\title{
Accelerated apoptosis contributes to aging-related hyperinflammation in endotoxemia
}

\author{
MIAN ZHOU, RONGQIAN WU, WEIFENG DONG, JENNIFER LEONG and PING WANG \\ The Feinstein Institute for Medical Research, and Department of Surgery, North Shore University Hospital \\ and Long Island Jewish Medical Center, Manhasset, NY 11030, USA
}

Received January 5, 2010; Accepted March 2, 2010

DOI: 10.3892/ijmm_00000424

\begin{abstract}
Sepsis is associated with an increase in circulating levels of bacterial endotoxin. Sepsis is a particularly serious problem in the geriatric population due to the associated high mortality rate. However, it remains unknown whether this phenomenon is related to an increase in apoptosis in splenic cells. To investigate this issue, male Fischer-344 rats (young, 3 months old; aged, 24 months old) were subjected to endotoxemia by injection of LPS. Splenic samples were collected $4 \mathrm{~h}$ thereafter. Apoptosis was determined by cleaved caspase- 3 levels and TUNEL staining. The levels of proinflammatory mediators, TNF- $\alpha$, IL- 6 and high mobility group box-1 (HMGB-1), were also measured. Our results showed that, while splenic cell apoptosis increased in the young and aged rats with endotoxemia, the aged animals had much higher levels of apoptotic cell death. The elevated expression of cell cycle inhibitory protein P21 was also observed in the aged animals after treatment with LPS. Moreover, endotoxemia significantly increased TNF- $\alpha$, IL-6 and HMGB-1. The accelerated apoptosis in the aged animals was correlated with significantly higher levels of TNF- $\alpha$, IL- 6 and HMGB- 1 . It is suggested that this accelerated rate of apoptosis contributes to age-related hyperinflammation in endotoxemia. To investigate the factors involving accelerated apoptosis in aged animals, we analyzed the Fas/Fas ligand (Fas-L) pathway. Our results showed that Fas and Fas-L gene expression was markedly higher in the spleen in the aged animals after LPS. Similarly, cleaved caspase- 8 expression, a downstream element of Fas and Fas-L, was also significantly higher in the aged rats after LPS. Fas-L neutralizing antibodies markedly decreased apoptosis and proinflammatory cytokines in the aged animals after endotoxemia. Thus, there is substantial evidence that the Fas/Fas-L pathway may play an important role in LPS-induced accelerated apoptosis and hyperinflammation in aged animals.
\end{abstract}

Correspondence to: Dr Ping Wang, Division of Surgical Research, The Feinstein Institute for Medical Research, 350 Community Drive, Manhasset, NY 11030, USA

E-mail: pwang@nshs.edu

Key words: aging, apoptosis, spleen, lipopolysaccharide, cytokines, caspase-3, Fas/Fas-ligand

\section{Introduction}

Sepsis, often caused by systemic immune responses to severe bacterial infection, can result in multiple organ failure and can even lead to death (1). A recent study revealed that the elderly ( $\geq 65$ years of age) account for only $12 \%$ of the US population but $65 \%$ of sepsis cases, yielding a much higher risk level compared to that of younger patients (2). Aging is characterized by changes in immune function and stress responses. It is associated with an increased susceptibility to infections as well as an increased incidence of autoimmune disorders and chronic inflammatory diseases $(3,4)$. The elderly have an increased incidence of complications and mortality following bacterial infection (1). Our recent data showed that levels of proinflammatory cytokines were much higher in aged animals after induction of endotoxemia, resulting in more severe organ damage and higher lethality (5). Thus, it appears that the alteration of immune responses in the aged population may contribute to a higher mortality rate after bacterial infection.

The pathogenesis of severe sepsis is characterized by tissue damage and accumulation of apoptotic lymphocytes in the spleen, thymus and other organs $(6,7)$. Studies suggest that apoptosis plays an important role in the immune dysfunction and multiple organ failure observed in sepsis or endotoxemia (8-10). However, it remains unknown whether there is any connection between increased immune cell apoptosis in the spleen and hyperinflammation [e.g., increased proinflammatory cytokines, such as TNF- $\alpha$, IL- 6 and high mobility group box 1 (HMGB-1)] in aged animals during bacterial infection. Thus, the objective of this study was to determine the relationship between immune cell apoptosis and proinflammatory cytokines in aged animals after injection of LPS. We also investigated a pathway which may be responsible for the elevation of apoptosis in aged animals under such conditions.

\section{Materials and methods}

Induction of endotoxemia in rats. Endotoxemia was induced by intravenous administration of lipopolysaccharide (LPS). Male Fischer-344 rats (young, 3 months old; aged, 24 months old) were obtained from the National Institute on Aging (NIA), housed in a temperature-controlled room on a 12-h light/dark cycle, and fed a standard Purina rat chow diet. Prior to the induction of severe endotoxemia, rats were fasted overnight but allowed water ad libitum. Rats were then 
anesthetized with isoflurane inhalation, their inguinal regions were shaved and washed with $10 \%$ povidone-iodine and a short subinguinal incision was made. The femoral vein was carefully separated from the artery and cannulated with a catheter (PE-50 tubing). A bolus injection of LPS $(15 \mathrm{mg} / \mathrm{kg}$ BW; E. coli 055:B5 in $200 \mu 1$ normal saline) (Sigma, St. Louis, MO) was administered through the femoral vein catheter. The same operation was performed on the vehicle control animals, but the control was injected with normal saline instead of LPS. Tissue samples were collected at $4 \mathrm{~h}$ after LPS injection. To note, the LPS dosage used in our studies (15 mg/kg BW) produces septic shock since $90 \%$ of the aged rats died within 5 days after LPS injection (unpublished data). The experiment described here was performed in adherence to the National Institutes of Health Guidelines for the Use of Experimental Animals. This project was approved by the Institutional Animal Care and Use Committee (IACUC) of The Feinstein Institute for Medical Research.

Administration of Fas ligand neutralizing antibodies. Endotoxemia was induced as described above. Fas ligand neutralizing antibodies or control IgG (R\&D Systems, Minneapolis, MN) were administered intravenously immediately after the administration of LPS. The dosage of the Fas ligand antibodies used was $200 \mu \mathrm{g} / \mathrm{kg}$ in $1 \mathrm{ml}$ saline (11) and was infused for $30 \mathrm{~min}$ with the use of an infusion pump. Splenic tissues were collected $4 \mathrm{~h}$ after LPS injection.

TUNEL assay. DNA breaks occur late in the apoptotic pathway and can be determined and analyzed by performing the terminal deoxynucleotide transferase dUTP nick end labeling (TUNEL) assay. The presence of apoptotic cells in the splenic tissues was demonstrated using a TUNEL staining kit (Roche Diagnostics, Indianapolis, IN). Briefly, splenic tissues were fixed in $10 \%$ phosphate-buffered formalin and were then embedded in paraffin and sectioned at $6-\mu \mathrm{m}$ following standard histology procedures. Spleen sections were dewaxed, rehydrated and equilibrated in Tris-buffered saline (TBS). The sections were then digested with $20 \mu \mathrm{g} / \mathrm{ml}$ proteinase $\mathrm{K}$ for $20 \mathrm{~min}$ at room temperature. Subsequently, the sections were washed and incubated with a mixture containing terminal deoxynucleotidyl transferase and fluorescence labeled nucleotides and examined under a fluorescence microscope. The negative control was performed by incubating slides in a mixture containing only deoxynucleotidyl transferase as recommended by the supplier.

Western blot analysis. Splenic tissues collected from animals at $4 \mathrm{~h}$ after LPS injection were homogenized in a lysis buffer, which contained protease inhibitor cocktail (1 tablet/10 ml) (Roche Diagnostics) in $10 \mathrm{mM}$ Tris saline (pH 7.5) with $1 \%$ Triton X-100. In addition, $1 \mathrm{mM}$ EDTA, $1 \mathrm{mM}$ EGTA, $2 \mathrm{mM}$ Na orthovanadate, $0.2 \mathrm{mM}$ PMSF, $2 \mu \mathrm{g} / \mathrm{ml}$ leupeptin and $2 \mu \mathrm{g} /$ $\mathrm{ml}$ aprotinin were added to the lysis buffer. After centrifugation at $16,000 \mathrm{x} \mathrm{g}$ for $10 \mathrm{~min}$, the supernatant was collected, and the protein concentration was determined by using a Bio-Red DC Protein Assay kit (Bio-Rad, Hercules, CA). Protein (36-75 $\mu \mathrm{g}$ ) from splenic tissue was separated by NuPage 4-12\% Bis-Tris gel (Invitrogen, Carlsbad, CA) in MES-SDS running buffer (Invitrogen). The protein on the gel was then transferred onto a nitrocellulose membrane and blocked with $5 \%$ nonfat dry milk in $10 \mathrm{mM}$ Tris saline with $0.1 \%$ Tween-20 (pH 7.5) (TBST). Western blotting was performed using the following primary antibodies: rabbit anti-cleaved caspase-3 polyclonal antibody $(1: 2,000)$ (Cell Signaling Technology, Danvers, MA), rabbit anti-caspase 8 polyclonal antibody (1:1000) (Santa Cruz Biotechnology, Santa Cruz, CA) and mouse anti-P21 monoclonal antibody (1:300) (Santa Cruz Biotechnology). After incubation of the primary antibodies overnight at $4^{\circ} \mathrm{C}$, the membranes were washed with TBST. Immunoreactive bands were detected using HRP-linked anti-rabbit IgG or HRP-linked anti-mouse $\operatorname{IgG}(1: 10,000)$ (SouthernBiotech, Birmingham, AL) and the Enhanced Chemiluminescence (ECL) Western blot detection kit (Amersham, Piscataway, NJ). The immunoblots were exposed to X-ray film and analyzed with a digital image system (Bio-Rad). Mouse anti- $\beta$-actin monoclonal antibody $(1: 20,000)$ (Sigma) was used as a loading control in all Western blot experiments.

Measurement of proinflammatory cytokines TNF- $\alpha, I L-6$ and $H M G B-1$. Splenic levels of TNF- $\alpha$ and IL-6 were quantified using an enzyme-linked immunosorbent assay (ELISA) kit specifically for rat TNF- $\alpha$ and IL-6 (BD Biosciences, San Diego, CA). Splenic tissues were homogenized in a lysis buffer, the supernatant was collected, and the protein concentrations were determined as described above. A 96-well plate was coated with a specific capture primary antibody for either rat TNF- $\alpha$ or IL-6. TNF- $\alpha$ (100 $\mu$ g protein/well) or IL-6 (20 $\mu \mathrm{g}$ protein/well) were loaded onto the pre-coated plate, and the assay was carried out according to the manufacturer's instructions. Circulating HMGB-1 levels were determined by Western blot analysis. Plasma $(2 \mu 1)$ in $10 \%$ SDS and loading buffer were boiled for $5 \mathrm{~min}$. The sample was then separated by a NuPage $4-12 \%$ gel (Invitrogen) and transferred to a nitrocellulose membrane. Western blotting was performed using rabbit anti-HMGB-1 primary antibodies (1:500) (a gift from Dr Haichao Wang at the Feinstein Institute for Medical Research) according to the Western blot procedures described above. We detected a HMGB-1 immunoreactive band at $30 \mathrm{kDa}$.

Real-time PCR analysis. Fas, Fas ligand and P21 gene expression was determined by real-time PCR (Q-PCR). Total RNA was extracted from splenic tissue using TRIzol reagent (Invitrogen). Q-PCR was carried out on cDNA samples reverse transcribed from $2 \mu \mathrm{g}$ RNA using murine leukemia virus reverse transcriptase (Applied Biosystems, Foster City, CA). Using a SYBR Green PCR Master Mix (Applied Biosystems), reactions were carried out in a $24-\mu 1$ final volume containing a $0.08-\mu$ mol concentration of each forward and reverse primer, $2 \mu \mathrm{l}$ cDNA, $9.2 \mu 1 \mathrm{H}_{2} \mathrm{O}$ and $12 \mu \mathrm{l}$ SYBR Green PCR Master Mix. Amplification was performed with an Applied Biosystems 7300 Real-Time PCR machine under the thermal profile of $50^{\circ} \mathrm{C}$ for $2 \mathrm{~min}, 95^{\circ} \mathrm{C}$ for $10 \mathrm{~min}$ followed by 40 cycles at $95^{\circ} \mathrm{C}$ for $15 \mathrm{sec}$ and $60^{\circ} \mathrm{C}$ for $1 \mathrm{~min}$. Rat GAPDH mRNA expression was used to normalize each sample, and analysis of each specific mRNA was conducted as duplicates. Relative expression of mRNA was calculated by the $2^{-\Delta \Delta \mathrm{Ct}}$ method, and results were expressed as fold 
Table I. Rat primers used in the present study.

\begin{tabular}{lll}
\hline Gene & \multicolumn{1}{c}{ Forward primer } & Reverse primer \\
\hline Fas (NM_139194) & AATGCTTCTCTCTGTGACACTGTTA & CAAGGCTCAAGGATGTCTTCAA \\
Fas-ligand (NM_012908) & TGCAGCAGCCCGTGAATT & GGAGAAGTGGCACTGCTGTCT \\
P21 (U24174) & CGGGACCGGGACATCTC & CGGCGCTTGGAGTGATAGAA \\
G3PDH (M17701) & ATGACTCTACCCACGGCAAG & CTGGAAGATGGTGATGGGTT \\
\hline
\end{tabular}

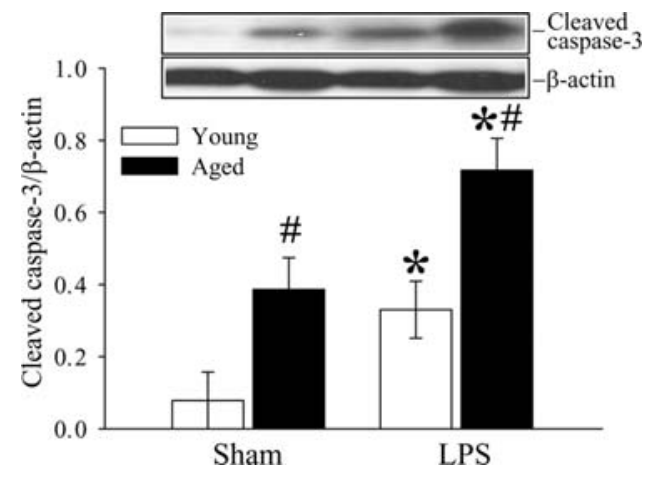

Figure 1. Alterations in splenic levels of cleaved caspase- 3 in young (3 months old) or aged (24 months old) rats at $4 \mathrm{~h}$ after normal saline (Sham) or LPS (LPS) injection. Representative gels are presented. Data are presented as means $\pm \mathrm{SE}$ ( $\mathrm{n}=5-6 /$ group) and compared by two-way analysis of variance (ANOVA) and the Student-Newman-Keuls test. ${ }^{*} \mathrm{P}<0.05$ versus the corresponding Sham group; ${ }^{\sharp} \mathrm{P}<0.05$ versus the young LPS group.

change with respect to the corresponding experimental control. The rat primers used in the experiment are listed in Table I. In order to assess the specificity of the PCR products, a melting curve analysis was performed in each Q-PCR experiment. We did not detect any non-specific products from any of the primers used in our experiments.

Statistical analysis. All data are expressed as means \pm SE and compared by one-way or two-way ANOVA and the StudentNewman-Keuls test. Differences in values were considered significant at $\mathrm{P}<0.05$.

\section{Results}

Alterations in splenic cell apoptosis. The extent of programmed cell death in the spleen was determined by cleaved caspase-3, Western blotting and TUNEL assay. As shown in Fig. 1, splenic levels of cleaved caspase-3 increased significantly in both the young and aged animals after LPS injection ( $\mathrm{P}<0.05$ vs. the respective sham). In addition, both basal and LPS-induced cleaved caspase-3 expression was much higher in the aged rats than in the young rats $(\mathrm{P}<0.05)$. DNA breaks occur late in the apoptotic process and are expressed by almost all cell types. The occurrence of DNA breaks can be detected by the TUNEL assay. As shown in Fig. 2, TUNEL-positive cells in the spleen increased markedly after LPS injection in both the young and aged rats. Similar to cleaved caspase- 3 expression, both basal and LPS-induced TUNEL-positive cells were more abundant in the aged rats
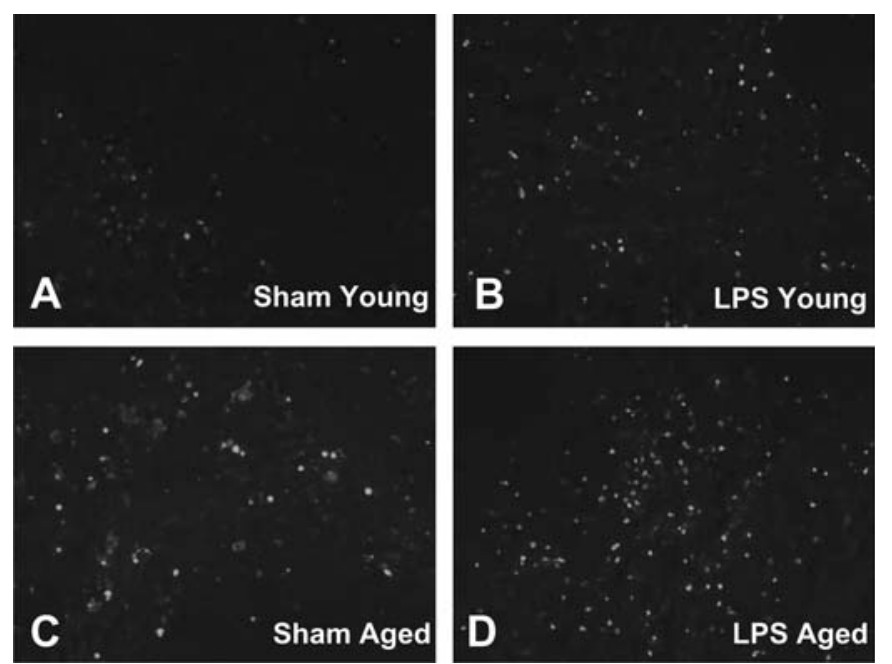

Figure 2. TUNEL staining in splenic tissues in young (3 months old) (A and B) or aged (24 months old) (C and D) rats at $4 \mathrm{~h}$ after normal saline (Sham) or LPS (LPS) injection. The TUNEL-positive cells were mainly located in the red pulp of the spleen, and aging animals showed a marked increase in the number of TUNEL-positive cells both in the Sham (C) and LPS (D) groups. Original magnification, $\mathrm{x} 200$.

than in the young rats. Thus, the cleaved caspase- 3 measurement and the TUNEL assay indicated an aging-related accelerated apoptosis of splenic cells during endotoxemia.

Alterations in P21 expression in the spleen. P21 is a cyclindependent kinase inhibitor which controls the cell cycle $(12,13)$. LPS significantly increased the splenic levels of the $\mathrm{P} 21$ gene $(\mathrm{P}<0.05)($ Fig. 3A) and protein $(\mathrm{P}<0.05)($ Fig. 3B) in both the young and aged animals. However, the increase in P21 expression in the aged animals was much higher than that in the young rats $(143 \%$ higher in gene expression and $206 \%$ higher in protein expression, $\mathrm{P}<0.05)$.

Alterations in the splenic levels of TNF- $\alpha$ and $I L-6$. Splenic levels of proinflammatory cytokines TNF- $\alpha$ and IL-6 were significantly elevated after administration of LPS (Fig. 4A and $\mathrm{B})$. Compared with those in the young rats, the levels of TNF- $\alpha$ (Fig. 4A) and IL-6 (Fig. 4B) were 4.1- and 1.9-fold higher, respectively, in the aged animals $(\mathrm{P}<0.05)$. Our results indicate that the aged animals had a much greater inflammatory response to bacterial endotoxin than the young animals.

Alterations in the circulating levels of $H M G B-1$. As indicated in Fig. 5, the circulating levels of HMGB-1 were 


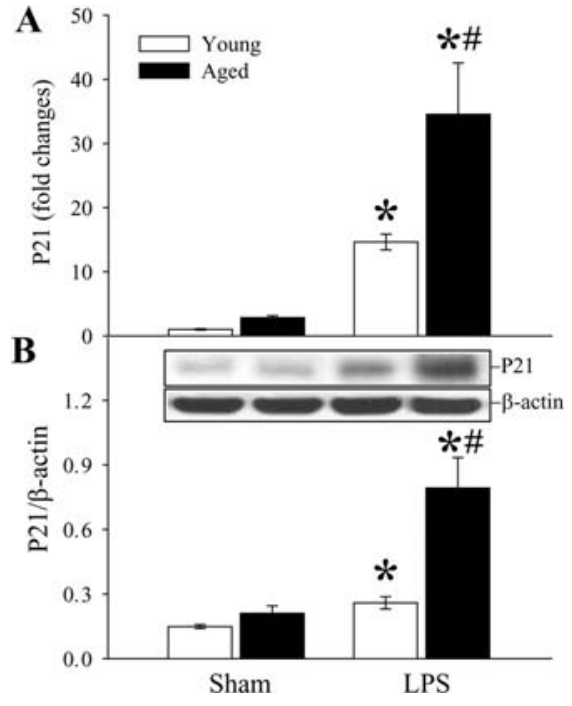

Figure 3. Alterations in splenic $\mathrm{P} 21$ gene (A) and protein (B) expression in young ( 3 months old) or aged (24 months old) rats at $4 \mathrm{~h}$ after normal saline (Sham) or LPS (LPS) injection. Representative gels are presented. Data are presented as means $\pm \mathrm{SE}$ ( $\mathrm{n}=5$-6/group) and compared by two-way analysis of variance (ANOVA) and the Student-Newman-Keuls test: " $\mathrm{P}<0.05$ versus the corresponding Sham group; ${ }^{\mathrm{P}} \mathrm{P}<0.05$ versus the young LPS group.

significantly elevated in both the young and aged animals after LPS injection. However, the circulating levels of HMGB-1 in the aged animals were markedly greater than those in the young animals after LPS injection.

Alterations in Fas and Fas ligand expression in the spleen. To determine the mechanism involved in splenic cell apoptosis, we examined the Fas/Fas-L pathway. As shown in Fig. 6A and B, Fas and Fas-L gene expression in the spleen was 1.6- and 10.1-fold higher, respectively, in the aged rats compared to expression in the young rats after LPS administration. The protein levels of Fas increased in both the young and aged animals after LPS injection $(\mathrm{P}<0.05)$ (Fig. 6C). However, Fas-L protein levels significantly increased only in the aged rats (Fig. 6D). The above data suggest that the Fas/ Fas-L pathway may be involved in accelerated apoptosis in aged animals after LPS injection.

Alterations in caspase- 8 levels in the spleen. Caspase- 8 is an important downstream caspase in the Fas/Fas-L pathway. Cleavage of caspase- 8 occurs following the activation of the Fas/Fas-L pathway, which leads to the activation of caspase-3 and subsequent apoptosis. As shown in Fig. 7, cleaved caspase- 8 was significantly upregulated in the aged animals after LPS injection $(\mathrm{P}<0.05)$. In contrast, the young animals showed only a slight increase in cleaved caspase-8 levels (no statistical significance, Fig. 7). We also observed higher cleaved caspase- 8 levels in the sham-operated aged rats as compared to the sham-operated young rats, but the increase was not statistically significant (Fig. 7).

Effects of Fas ligand neutralizing antibodies. To determine whether the Fas/Fas-L pathway plays a role in accelerated apoptosis in aged rats, Fas-L neutralizing antibodies were

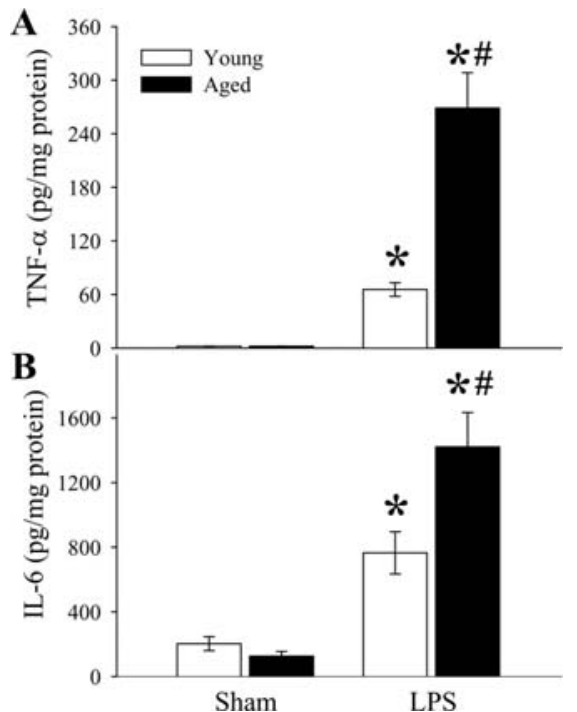

Figure 4. Alterations in splenic levels of TNF- $\alpha$ (A) and IL-6 (B) in young (3 months old) or aged (24 months old) rats at $4 \mathrm{~h}$ after normal saline (Sham) or LPS (LPS) injection. Data are presented as means \pm SE $(n=5$ 6/group) and compared by two-way analysis of variance (ANOVA) and the Student-Newman-Keuls test: ${ }^{*} \mathrm{P}<0.05$ versus corresponding Sham group; ${ }^{\#} \mathrm{P}<0.05$ versus the young LPS group.

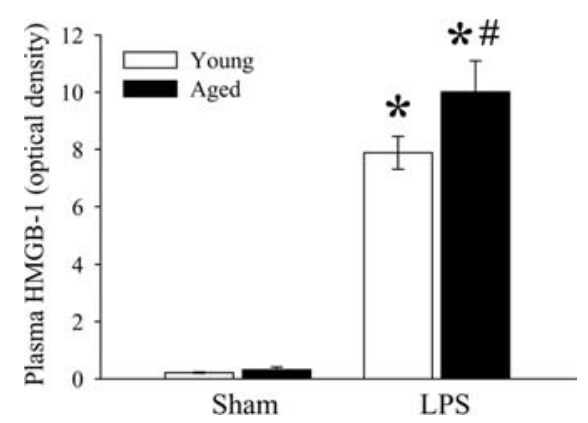

Figure 5. Alterations in plasma levels of HMGB-1 in young ( 3 months old) or aged (24 months old) rats at $4 \mathrm{~h}$ after normal saline (Sham) or LPS (LPS) injection. Data are presented as means \pm SE ( $n=5-6 /$ group) and compared by two-way analysis of variance (ANOVA) and the Student-Newman-Keuls test: ${ }^{*} \mathrm{P}<0.05$ versus corresponding Sham group; ${ }^{\#} \mathrm{P}<0.05$ versus the young LPS group.

administered immediately after LPS injection. As indicated in Fig. 8, Fas-L neutralizing antibodies reduced cleaved caspase-3 to levels similar to those of the sham-operated animals $(\mathrm{P}<0.05)$. Thus, inhibition of the Fas/Fas-L pathway attenuated splenic cell apoptosis. As indicated in Fig. 9, administration of Fas-L neutralizing antibodies at the time of LPS injection reduced splenic levels of TNF- $\alpha$ in the aged animal by $50 \%(\mathrm{P}<0.05$ vs. vehicle). In contrast, levels of TNF- $\alpha$ in the young rats remained unchanged after treatment (Fig. 9). Treatment with Fas-L antibodies also decreased circulating HMGB-1 levels by $40.3 \%$ in the young and $46.5 \%$ in the aged animals (Fig. 10). Thus, inhibition of apoptosis by blocking the Fas/Fas-L pathway is associated with a significant decrease in aging-related LPS-induced TNF- $\alpha$ and HMGB-1 production. 

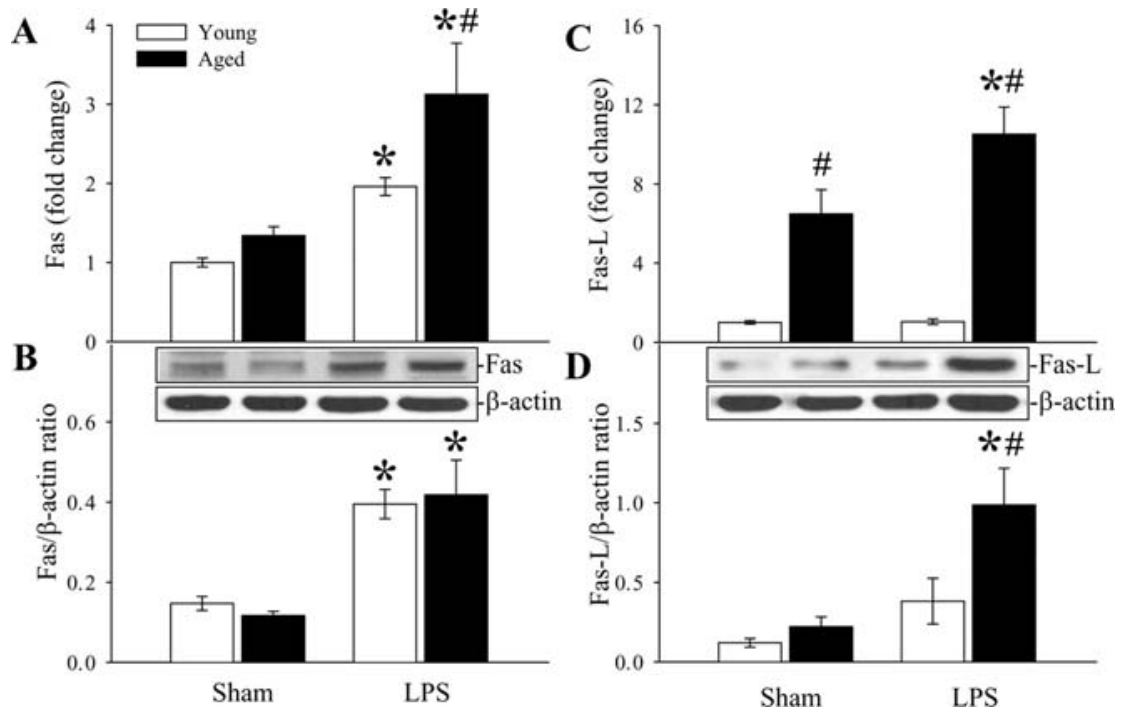

Figure 6. Alterations in Fas (A), Fas ligand (C) gene expression and Fas (B), Fas ligand (D) protein levels in the spleen of young (3 months old) or aged (24 months old) rats at $4 \mathrm{~h}$ after normal saline (Sham) or LPS (LPS) injection. Representative blots are presented. Data are presented as means \pm SE ( $\mathrm{n}=5-6 / \mathrm{group}$ ) and compared by two-way analysis of variance (ANOVA) and the Student-Newman-Keuls test: ${ }^{*} \mathrm{P}<0.05$ versus the corresponding Sham group; ${ }^{*} \mathrm{P}<0.05$ versus the young LPS group.

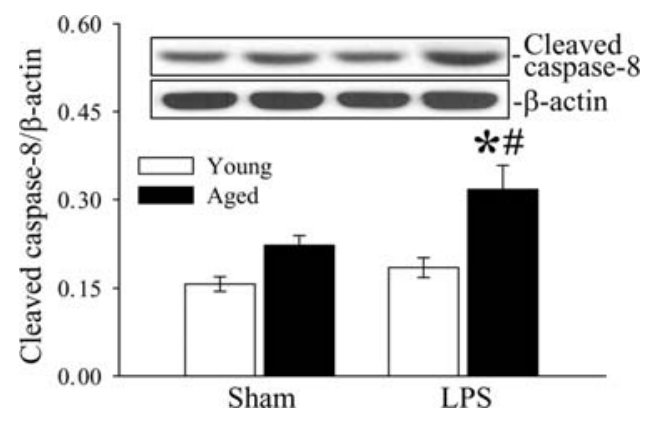

Figure 7. Alterations in splenic caspase- 8 in young ( 3 months old) or aged (24 months old) rats at $4 \mathrm{~h}$ after normal saline (Sham) or LPS (LPS) injection. Representative blots are presented. Data are presented as means \pm $\mathrm{SE}$ ( $\mathrm{n}=5$-6/group) and compared by two-way analysis of variance (ANOVA) and the Student-Newman-Keuls test: ${ }^{*} \mathrm{P}<0.05$ versus the corresponding Sham group; ${ }^{\mathrm{P}} \mathrm{P}<0.05$ versus the young LPS group.

\section{Discussion}

Sepsis is a particularly serious problem in the geriatric population. Nearly $60 \%$ of all cases of sepsis occur in patients older than 65 years of age; also the mortality rate due to sepsis significantly increases with age, from $10-15 \%$ in patients 20-29 years of age to $38.4 \%$ in those over 85 years of age $(1,2)$. Aging in human and animal models have revealed changes in many aspects of protective immunity during sepsis $(4,14,15)$. It is assumed that the increased incidence and mortality rate of sepsis in the elderly is a direct result of an impaired immune response. We recently reported that LPS injection causes an in vivo hyperinflammatory state in aged animals, characterized by a further increase in proinflammatory cytokines and more severe tissue injury (5). The present results also indicate that splenic levels of proinflammatory cytokines, TNF- $\alpha$, IL-6 and circulating levels of HMGB-1, are markedly elevated in aged animals

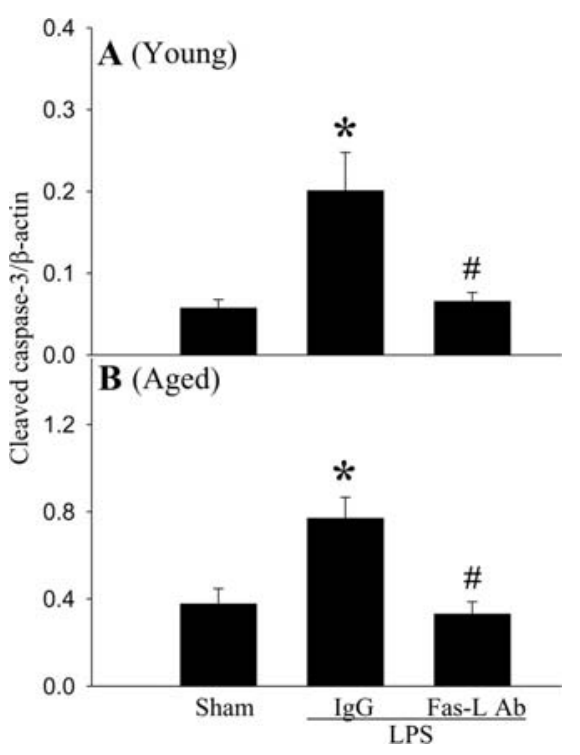

Figure 8. Alterations in splenic levels of cleaved caspase-3 in young (3 months old) (A) or aged (24 months old) (B) rats at $4 \mathrm{~h}$ after normal saline (Sham) or LPS (LPS) injection treated with normal IgG (IgG) or Fas-L neutralizing antibodies (Fas-L Ab). Data are presented as means \pm SE (n=4-5/group) and compared by one-way analysis of variance (ANOVA) and the StudentNewman-Keuls test: ${ }^{*} \mathrm{P}<0.05$ versus the corresponding Sham group; ${ }^{\text {}} \mathrm{P}<0.05$ versus the corresponding LPS+IgG group.

and are much higher than in young animals after LPS administration. In this study, we focused on apoptotic immune cell death because of its crucial role in immune dysfunction and multiple organ failure during sepsis (810,16).

In the present study, we examined the effect of splenic cell apoptosis on the innate response, as well as the effects of Fas/Fas-L and caspase- 8 as a signaling pathway by which apoptosis was activated. We found that aged septic animals 


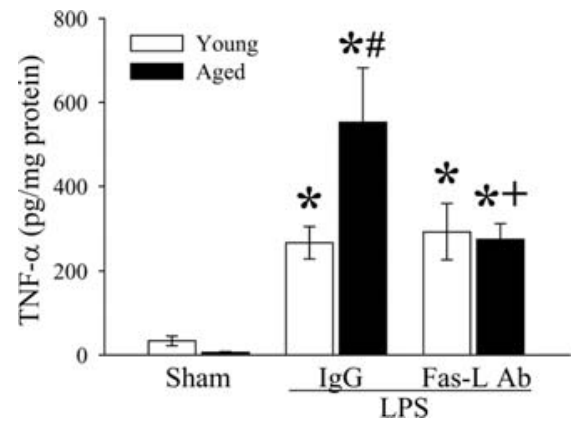

Figure 9. Alterations in splenic levels of TNF- $\alpha$ in young (3 months old) or aged (24 months old) rats at $4 \mathrm{~h}$ after normal saline (Sham) or LPS (LPS) injection treated with normal IgG (IgG) or Fas-L neutralizing antibodies (Fas-L Ab). Data are presented as means \pm SE ( $n=4-5 /$ group) and compared by two-way analysis of variance (ANOVA) and the Student-Newman-Keuls test: ${ }^{*} \mathrm{P}<0.05$ versus the corresponding Sham group; ${ }^{\#} \mathrm{P}<0.05$ versus the young $\mathrm{LPS}+\mathrm{IgG}$ group; ${ }^{+} \mathrm{P}<0.05$ versus the aged $\mathrm{LPS}+\mathrm{IgG}$ group.

had increased splenic cell apoptosis and higher levels of P21 as compared to either the young septic animals or the aged sham animals. It was revealed that upregulation of P21, a cyclin-dependent kinase inhibitor, could result in cell cycle arrest and apoptosis $(12,13)$. Therefore, significantly higher levels of P21 in aged animals may contribute to higher apoptosis levels in those animals after endotoxemia. Most importantly, we found that aging-related hyperinflammation was associated with splenic cell apoptosis. Splenic Fas-L expression was markedly higher in the aged animals, indicating an impairment of the death receptor-related Fas/Fas-L apoptotic pathway. When we administered Fas-L neutralizing antibodies at the time of LPS injection, splenic apoptosis was significantly attenuated, and the aging-related elevation of TNF- $\alpha$ and HMGB-1 was also prevented. The aforementioned results clearly show that accelerated apoptosis contributes to age-related hyperinflammation during endotoxemia. Hiramatsu et al (17) and Hotchikiss et al (18) reported that an increase in splenic lymphocyte apoptosis in septic mice is associated with an increase in mortality. This phenomenon may be related with the upregulation of proinflammatory cytokines following splenic cell apoptosis. Since the Fas/Fas-L pathway plays an important role in agerelated splenic apoptosis in endotoxemia, attenuating its activation may reduce age-related mortality in sepsis or bacterial infection.

Both aging and sepsis independently increase splenic cell apoptosis. Immune cells that undergo programmed cell death include various lymphocyte populations, macrophages, dendritic cells and neutrophils (4,19-21). Apoptotic loss of immune effector cells such as CD4 T and B cells is a key factor in the loss of immune competence in sepsis $(22,23)$. An increase in splenic lymphocyte apoptosis in septic mice is thus associated with an increase in mortality $(17,18)$. It has been reported that lymphocyte apoptosis is increased in CD4 and CD8 T cells, CD20 B cells, and NK cells (CD56) in septic patients as compared to their nonseptic counterparts (24). Samples taken from patients with sepsis also show that the level of CD3 T cell apoptosis correlates with the degree of severity of sepsis (24). Although we did not determine the cell population that underwent programmed cell death in the

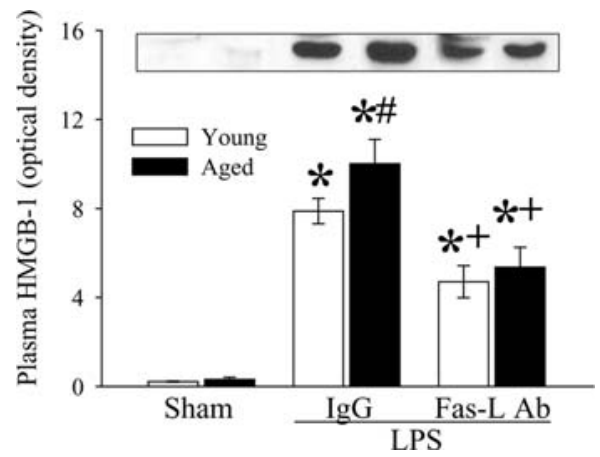

Figure 10. Alterations in circulating HMGB-1 levels in young (3 months old) or aged (24 months old) rats at $4 \mathrm{~h}$ after normal saline (Sham) or LPS (LPS) injection treated with normal $\mathrm{IgG}(\mathrm{IgG})$ or Fas-L neutralizing antibodies (Fas-L Ab). A representative blot is presented. Data are presented as means \pm SE ( $n=4-5 /$ group) and compared by two-way analysis of variance (ANOVA) and the Student-Newman-Keuls test: ${ }^{*} \mathrm{P}<0.05$ versus the corresponding Sham group; ${ }^{\text {}} \mathrm{P}<0.05$ versus the young $\mathrm{LPS}+\mathrm{IgG}$ group; $+\mathrm{P}<0.05$ versus the aged $\mathrm{LPS}+\operatorname{IgG}$ group.

present study, our preliminary data show that a significantly larger number of splenic $\mathrm{CD}^{+} \mathrm{T}$ cells underwent apoptosis in the aged animals after LPS injection. Thus, it appears that lymphocyte apoptosis does occur in aged animals after LPS injection. Thus, it is in this way that the combination of aging and bacterial infection leads to a disproportionate increase in immune cell death and alters the immune response, a factor which potentially plays a role in the marked increase in mortality noted in sepsis in the elderly.

Mammalian apoptotic cell death in sepsis proceeds through two distinct pathways, the death receptor pathway and the mitochondrial pathway, that converge to activate caspases, resulting in intracellular demolition $(25,26)$. The extrinsic, or death receptor, pathway is triggered by signaling through TNF, Trail and Fas $(19,27,28)$. The mitochondrial (intrinsic) death pathway responds to various stress stimuli, e.g. oxidative stress, radiation, and cytokine withdrawal (26). Both the death receptor and mitochondrial pathways are activated in sepsis $(22,24)$. Although mediators such as steroids, tumor necrosis factor, nitric oxide, C5a and Fas-L appear to contribute to the changes that occur during apoptosis, their effects are tissue and cell population-selective $(19,29)$. Fas/ Fas-L belongs to the death receptor-mediated apoptosis pathway, which is heavily involved in lymphocyte apoptosis $(9,29)$. Hsu et al reported that the Fas/Fas-L pathway is impaired in aged animals, and Fas-L-mediated apoptosis plays a major role in activation-induced cell death of $\mathrm{T}$ cells (30). Our current data indicated that without LPS stimulation, splenic Fas-L expression was markedly higher in the aged animals than in the young animals. LPS administration further elevated expression of Fas-L in the aged animals. The present study also revealed significantly upregulated levels of caspase 8 in these aged animals after LPS injection, indicating that the Fas/Fas-L pathway may play an important role in programmed cell death in aged animals. Inhibition of the Fas/Fas-L pathway by Fas-L neutralizing antibodies attenuated splenic cell apoptosis in aged rats, further supporting the idea that this pathway plays an important role in age-related accelerated apoptosis after LPS injection. 
In summary, while splenic cell apoptosis increased in both the young and aged rats during endotoxemia, aged animals had much higher levels of apoptotic cell death. This accelerated apoptosis in the aged animals corresponded with significantly higher levels of TNF- $\alpha$, IL-6 and HMGB-1. Moreover, the expression of Fas, Fas-L and caspase- 8 was markedly higher in the spleens of the aged animals than that in the young animals after LPS injection. Fas-L neutralizing antibodies repressed apoptosis and proinflammatory cytokines in the aged animals after endotoxemia. Therefore, it is suggested that accelerated apoptosis contributes to age-related hyperinflammation in endotoxemia. The Fas/Fas-L pathway may play an important role in LPS-induced accelerated apoptosis and hyperinflammation in aged animals.

\section{Acknowledgements}

This study was supported by the National Institutes of Health grants R01 AG028352, R01 GM053008 and R01 GM057468 (P. Wang). We thank Michael Miksa and Hidefumi Komura for their assistance.

\section{References}

1. Angus DC, Linde-Zwirble WT, Lidicker J, Clermont G, Carcillo J and Pinsky MR: Epidemiology of severe sepsis in the United States: analysis of incidence, outcome, and associated costs of care. Crit Care Med 29: 1303-1310, 2001.

2. Martin GS, Mannino DM and Moss M: The effect of age on the development and outcome of adult sepsis. Crit Care Med 34: 15-21, 2006.

3. Deng Y, Jing Y, Campbell AE and Gravenstein S: Age-related impaired type $1 \mathrm{~T}$ cell responses to influenza: reduced activation ex vivo, decreased expansion in CTL culture in vitro, and blunted response to influenza vaccination in vivo in the elderly. J Immunol 172: 3437-3446, 2004.

4. Weiskopf D, Weinberger B and Grubeck-Loebenstein B: The aging of the immune system. Transpl Int 22: 1041-1050, 2009.

5. Wu R, Zhou M, Dong W, Ji Y, Miksa M, Marini CP, Ravikumar TS and Wang P: Ghrelin hyporesponsiveness contributes to age-related hyperinflammation in septic shock. Ann Surg 250: 126-133, 2009.

6. Qin S, Wang H, Yuan R, Li H, Ochani M, Ochani K, RosasBallina M, Czura CJ, Huston JM, Miller E, Lin X, Sherry B, Kumar A, Larosa G, Newman W, Tracey KJ and Yang H: Role of HMGB1 in apoptosis-mediated sepsis lethality. J Exp Med 203: 1637-1642, 2006

7. Huston JM, Wang H, Ochani M, Ochani K, Rosas-Ballina M, Gallowitsch-Puerta M, Ashok M, Yang L, Tracey KJ and Yang H: Splenectomy protects against sepsis lethality and reduces serum HMGB1 levels. J Immunol 181: 3535-3539, 2008.

8. Chung CS, Yang S, Song GY, Lomas J, Wang P, Simms HH, Chaudry IH and Ayala A: Inhibition of Fas signaling prevents hepatic injury and improves organ blood flow during sepsis. Surgery 130: 339-345, 2001.

9. Chung CS, Song GY, Lomas J, Simms HH, Chaudry IH and Ayala A: Inhibition of Fas/Fas ligand signaling improves septic survival: differential effects on macrophage apoptotic and functional capacity. J Leukoc Biol 74: 344-351, 2003.

10. Hotchkiss RS, Swanson PE, Freeman BD, Tinsley KW, Cobb JP Matuschak GM, Buchman TG and Karl IE: Apoptotic cell death in patients with sepsis, shock, and multiple organ dysfunction. Crit Care Med 27: 1230-1251, 1999.
11. Zacks DN, Zheng QD, Han Y, Bakhru R and Miller JW: FASmediated apoptosis and its relation to intrinsic pathway activation in an experimental model of retinal detachment. Invest Ophthalmol Vis Sci 45: 4563-4569, 2004.

12. Min LJ, Mogi M, Iwai M and Horiuchi M: Signaling mechanisms of angiotensin II in regulating vascular senescence. Ageing Res Rev 8: 113-121, 2009.

13. Prives $\mathrm{C}$ and Gottifredi V: The p 21 and PCNA partnership: a new twist for an old plot. Cell Cycle 7: 3840-3846, 2008.

14. Sawhney M, Mathew M, Valarmathi MT and Das SN: Age related changes in Fas (CD95) and Fas ligand gene expression and cytokine profiles in healthy Indians. Asian Pac J Allergy Immunol 24: 47-56, 2006.

15. Grolleau-Julius A, Ray D and Yung RL: The role of epigenetics in aging and autoimmunity. Clin Rev Allergy Immunol (In press).

16. Hotchkiss RS, Tinsley KW and Karl IE: Role of apoptotic cell death in sepsis. Scand J Infect Dis 35: 585-592, 2003.

17. Hiramatsu M, Hotchkiss RS, Karl IE and Buchman TG: Cecal ligation and puncture (CLP) induces apoptosis in thymus, spleen, lung, and gut by an endotoxin and TNF-independent pathway. Shock 7: 247-253, 1997.

18. Hotchkiss RS, Swanson PE, Cobb JP, Jacobson A, Buchman TG and Karl IE: Apoptosis in lymphoid and parenchymal cells during sepsis: findings in normal and T- and B-cell-deficient mice. Crit Care Med 25: 1298-1307, 1997.

19. Wesche DE, Lomas-Neira JL, Perl M, Chung CS and Ayala A: Leukocyte apoptosis and its significance in sepsis and shock. J Leukoc Biol 78: 325-337, 2005

20. Hsu HC, Scott DK, Zhang P, Zhou J, Yang P, Wu Q, Schroeder HW Jr, Gerald LB, Ravussin E, Jazwinski SM and Mountz JD: CD8 T-cell immune phenotype of successful aging. Mech Ageing Dev 127: 231-239, 2006.

21. Tinsley KW, Grayson MH, Swanson PE, Drewry AM, Chang KC Karl IE and Hotchkiss RS: Sepsis induces apoptosis and profound depletion of splenic interdigitating and follicular dendritic cells. J Immunol 171: 909-914, 2003.

22. Brahmamdam P, Watanabe E, Unsinger J, Chang KC, Schierding W, Hoekzema AS, Zhou TT, McDonough JS, Holemon H, Heidel JD, Coopersmith CM, McDunn JE and Hotchkiss RS: Targeted delivery of siRNA to cell death proteins in sepsis. Shock 32: 131-139, 2009.

23. Parrino J, Hotchkiss RS and Bray M: Prevention of immune cell apoptosis as potential therapeutic strategy for severe infections. Emerg Infect Dis 13: 191-198, 2007.

24. Hotchkiss RS, Osmon SB, Chang KC, Wagner TH, Coopersmith CM and Karl IE: Accelerated lymphocyte death in sepsis occurs by both the death receptor and mitochondrial pathways. J Immunol 174: 5110-5118, 2005

25. Chang KC, Unsinger J, Davis CG, Schwulst SJ, Muenzer JT, Strasser A and Hotchkiss RS: Multiple triggers of cell death in sepsis: death receptor and mitochondrial-mediated apoptosis. FASEB J 21: 708-719, 2007.

26. Roy S and Nicholson DW: Cross-talk in cell death signaling. J Exp Med 192: F21-F25, 2000.

27. Lavrik I, Golks A and Krammer PH: Death receptor signaling. J Cell Sci 118: 265-267, 2005.

28. Thorburn A: Death receptor-induced cell killing. Cell Signal 16: 139-144, 2004.

29. Maher S, Toomey D, Condron C and Bouchier-Hayes D: Activation-induced cell death: the controversial role of Fas and Fas ligand in immune privilege and tumour counterattack. Immunol Cell Biol 80: 131-137, 2002.

30. Hsu HC, Scott DK and Mountz JD: Impaired apoptosis and immune senescence - cause or effect? Immunol Rev 205: 130-146, 2005. 